\title{
The impact of inocula carryover and inoculum dilution on the methane yields in batch methane potential tests
}

\author{
by Reilly, M., Dinsdale, R. and Guwy, A.
}

Copyright, Publisher and Additional Information: Author's accepted manuscript published subsequently by Elsevier in Bioresource Technology. Article available under the terms of the CC-BY-NC-ND licence (https://creativecommons.org/licenses/by-nc-nd/4.0/)

DOI: 10.1016/j.biortech.2016.02.060

\section{A note on versions:}

The version presented here may differ from the published version or, version of record, if you wish to cite this item you are advised to consult the publisher's version.

\section{Harper Adams}

University

Reilly, M., Dinsdale, R. and Guwy, A. 2016. The impact of inocula carryover and inoculum dilution on the methane yields in batch methane potential tests. Bioresource Technology, 2008, pp. 134-139. 
Bi or esource Technol ogy

El sevi er Edi torial System(t m) for

\section{Manuscript Draft}

Manuscri pt Number: BI TE- D-16-00350R1

Title: The i mpact of i nocul a carryover and i nocul um di l ut i on on the met hane yi el ds i $n$ bat ch met hane pot ent $i$ al test $s$

Arti cl e Type: Ori gi nal research paper

Keywor ds: Bi omet hane; Bi ohydrogen; Dark fer ment at i on; Two-st age anaer obi c di gest i on; Bat ch st udi es.

Cor responding Aut hor: Dr. Mat thew Rei II y,

Corresponding Author's I nst ituti on: Harper Adans Uni versity

First Aut hor: Mat thew Rei II y

Order of Aut hors: Mat thew Rei II y; Ri chard Di nsdal e, BSc, PhD; Al an Guny, BSc, PhD

Abst ract: Batch studi es are used to benchmark bi ohydrogen pot ent i al (BHP) and bi omet hane potenti al (BMP) yi el ds fromfeed substrates, di gestates resi dues and different process confi gurations. Thi s st udy shows that BMP yi el ds using cell ul ose can be bi ased positi vel y by not di I uting the i nitial sewage sl udge i nocul umand the bi as is i ndependent of starting i nocul um vol at ile sol ids (VS) concentration. The carryover of BHP i nocul umal so i ncreased the BMP yi el ds when using cell ul ose as a substrate by up to 18. 8\% Furthernore it was al so observed that the di I ut i on of BMP i nocul um wi th dei oni sed $\mathrm{H} 2 \mathrm{O}$ reduced methane yi el ds from cel I ul ose by up to $132 \pm 26 \mathrm{Nm}-\mathrm{CH} 4 \mathrm{~g}$-VS- 1 . Ther ef ore it is proposed that i nocul um and standard substrate controls (as used in thi s study) should be i ncl uded in methane batch methodol ogi es, particul arly when usi ng a pre-ferment at i on stage such as dark fermentation. 


\section{HIGHLIGHTS}

Total methane yield from cellulose was influenced by the inoculum volume.

Diluted inoculum led to decreased methane yields from cellulose standards.

Inoculum volume influences batch comparisons of single and two stage biogas yields.

Inoculum carryover from pre-fermentation raised batch methane yields from cellulose.

Batch methane yields should include substrate control values for different inoculums. 
The impact of inocula carryover and inoculum dilution on the methane yields in batch methane potential tests

\title{
Matthew Reilly ${ }^{a} *$, Richard Dinsdale ${ }^{b}$, Alan Guwy ${ }^{b}$
}

${ }^{a}$ Agricultural Centre for Sustainable Energy Systems (ACSES), Harper Adams

University, Newport, Shropshire, TF10 8NB, United Kingdom

${ }^{\mathrm{b}}$ Sustainable Environment Research Centre (SERC), Faculty of Computing, Engineering and Science, University Of South Wales, Upper Glyntaff, Pontypridd, CF37 1BD, United Kingdom

*Corresponding author. Tel: +44 1952 815489; fax: +44 1952 814783; e-mail address: mreilly@ harper-adams.ac.uk

\begin{abstract}
Batch studies are used to benchmark biohydrogen potential (BHP) and biomethane potential (BMP) yields from feed substrates, digestates residues and different process configurations. This study shows that BMP yields using cellulose can be biased positively by not diluting the initial sewage sludge inoculum and the bias is independent of starting inoculum volatile solids (VS) concentration. The carryover of BHP inoculum also increased the BMP yields when using cellulose as a substrate by up to $18.8 \%$. Furthermore it was also observed that the dilution of BMP inoculum with deionised $\mathrm{H}_{2} \mathrm{O}$ reduced methane yields from cellulose by up to $132 \pm 26 \mathrm{NmL}^{-\mathrm{CH}_{4}} \mathrm{~g}-\mathrm{VS}^{-1}$. Therefore it is proposed that inoculum and standard substrate controls (as used in this study) should be included in methane batch methodologies, particularly when using a pre-fermentation stage such as dark fermentation.
\end{abstract}




\section{Keywords}

Biomethane; Biohydrogen; Dark fermentation; Two-stage anaerobic digestion; Batch studies.

\section{Introduction}

During anaerobic digestion, microbes are able to convert a wide range of organic materials to biogas fuel (Angelidaki et al., 2009). The energy collected from anaerobic digestion is considered to be renewable and environmentally friendly, due to organic substrates acting as the precursors for fuel production (Wang et al., 2015). At present, industrial anaerobic digestion is most commonly operated to produce a biogas, which is rich in methane and $\mathrm{CO}_{2}$. However in recent years there has been increased interest from the scientific community in preceding anaerobic digestion with a dark fermentation stage, to form a two-stage process (Giordano et al., 2011; Mamimin et al., 2015; Massanet-Nicolau et al., 2013; Pakarinen et al., 2009). The process of dark fermentation is also able to utilise a vast array of organic materials, although the end products differ to anaerobic digestion and are $\mathrm{H}_{2}, \mathrm{CO}_{2}$ and volatile fatty acids (VFA) (Reilly et al., 2014).

A number of investigators have examined if overall energy yields can be increased from using two-stage systems using a variety of substrates. Kim et al., (2013) observed a $59.4 \%$ higher energy yield from two-stage digestion of co-digested untreated rice straw mixed with sewage sludge, compared to when single-stage anaerobic digestion was operated. Liu et al., (2014) reported an average increase in energy yield of $26 \%$ over single-stage digestion, when two-stage digestion of steam-exploded cornstalk was tested. Yang et al., (2011) performed two-stage digestion on micro algal biomass 
residues and measured a $22 \%$ increase in biomethane production compared to singlestage anaerobic digestion. This was in addition to $46 \mathrm{~mL}-\mathrm{H}_{2} \mathrm{~g}-\mathrm{VS}^{-1}$ which had already been achieved in the dark fermentation stage. Pakarinen et al., (2009) investigated twostage $\mathrm{H}_{2}$ and $\mathrm{CH}_{4}$ production from grass silage. The authors found that $8 \%$ more methane was obtained from operation of two-stage compared to using a single-stage process, when raw grass silage was fed. In addition, the dark fermentation stage was able to produce $5.6 \mathrm{~mL}-\mathrm{H}_{2} \mathrm{~g}-\mathrm{VS}^{-1}$. Pakarinen et al., (2011) compared single-stage anaerobic digestion and two-stage batch digestion of $\mathrm{HCl}$ pre-treated, water extraction pre-treated and untreated maize. The overall energy generated from two-stage yields was reported to be $27 \%, 9.2 \%$ and $7.1 \%$ higher than from single-stage comparisons, respectively. In a direct comparative study of single-stage and two-stage anaerobic digestion of a lignocellulosic feedstock (the wheat milling industry co-product, wheat feed) the two-stage anaerobic digestion was found to increase the energy yield by $37 \%$ compared to single-stage anaerobic digestion (Massanet-Nicolau et al., 2013).

Even though multiple studies have suggested that two-stage processes provide advantages, a number of studies have also reported similar or even better energy yields from single-stage anaerobic digestion. These variations are particularly apparent from results recently published by Schievano et al., (2014) in which two-stage yields were only significantly greater than single-stage comparisons in close to $50 \%$ of cases considered. Kaparaju et al., (2009) reported in their study that the yields from singlestage anaerobic digestion and two-stage digestion of hydrolysate from thermally pretreated wheat straw were "more or less the same". Furthermore, Patterson et al., (2013) recommended the use of single-stage anaerobic digestion of food waste because their 
life cycle analysis found that it was more energetically efficient than using a two-stage process.

There is a significant amount of evidence that can be found in the literature which favours the operation of two-stage processes (Massanet-Nicolau et al., 2013). However, an exhaustive explanation for why higher energy yields are possible from two-stage systems remains elusive. One proposal is that the conversion of VFA in the methanogenesis-stage is more efficient than in single-stage anaerobic digestion (Liu et al., 2006). Alternatively, Massanet-Nicolau et al., (2013) hypothesised that the $37 \%$ increase in energy yield which they achieved by using a two-stage system was because the dark fermentation stage limits the conversion of substrate in metabolic pathways which would otherwise compete with methanogenesis.

Due to the small footprint and low cost of equipment a large number of anaerobic digestion experiments have been completed using batch type methodologies rather than continuous operation (Angelidaki et al., 2009). In single-stage batch experiments it is common practise to load inoculum and substrate based on VS ratios (Devlin et al., 2011; Pakarinen et al., 2011, 2009). Therefore, the influence of the VS ratio of inoculum to feed substrates on single-stage biomethane production has been commonly investigated during batch tests (Raposo et al., 2009; Liu et al., 2009; Eskicioglu \& Ghorbani 2011; Alzate et al., 2012; Dechrugsa et al., 2013). Alternatively, in two-stage batch studies a constant volume of methanogenic inoculum has often been used for biomethane production (Cheng and Liu, 2012; Giordano et al., 2014; Kim et al., 2013; Pakarinen et al., 2009; Xie et al., 2008; Yang et al., 2011). Typically predetermined volumes of dark fermentation effluent and methanogenic inoculum are mixed to initiate 
methanogenesis in two-stage experiments (Giordano et al., 2011; Kim et al., 2013; Pakarinen et al., 2011, 2009; Wang et al., 2015; Yang et al., 2011). For single-stage controls the same volume of methanogenic inoculum is added to feed substrate in a separate bioreactor and then $\mathrm{H}_{2} \mathrm{O}$ is used to make up the remainder of the working volume (Kim et al., 2013; Pakarinen et al., 2011, 2009; Yang et al., 2011). In both single-stage and two-stage batch tests the specific yields from feed substrates are often calculated by subtracting any residual biogas produced from inoculum controls, which are commonly termed "blanks" (Cheng and Liu, 2012; Devlin et al., 2011; Giordano et al., 2011; Kim et al., 2012; Pakarinen et al., 2011, 2009). These blanks are setup using the same volumes of dark fermentation and methanogenic inoculum, with the volume of the feed substrate being replaced with $\mathrm{H}_{2} \mathrm{O}$.

Therefore, in two-stage batch experiments the biomethane bioreactors contain elements, which are derived from methanogenic inoculum, dark fermentation inoculum and feed substrates. In comparison the single-stage methanogenic batch bioreactors commonly contain methanogenic inoculum, feed substrate and are diluted with $\mathrm{H}_{2} \mathrm{O}$ to compensate the working volume. The novel aim of the current study was to compare the influences on biomethane yields between the carryover of dark fermentation inoculum or the addition of $\mathrm{H}_{2} \mathrm{O}$ to the BMP tests. This work was carried out to investigate if there is a need to control for the presence of dark fermentation inoculum which is carried over into methanogenesis during two-stage batch studies. Furthermore the dilution of singlestage batch anaerobic digestion with $\mathrm{H}_{2} \mathrm{O}$ was investigated to determine if this can limit potential biomethane yields. These contributions to knowledge are particularly important to consider when designing a batch methodology to compare substrate yields between single-stage and two-stage anaerobic digestion. 


\section{Materials and Methods}

\subsection{Raw materials}

Sucrose was obtained from Sigma Aldrich (84100-1KG, Sigma Aldrich Company Ltd., UK). High purity cellulose microcrystalline powder was also acquired from Sigma Aldrich Company Ltd., UK (435236-1KG). Sucrose was used as a control for dark fermentation experiments (Reilly et al., 2014). Cellulose was used as a control and feed substrate in biomethane experiments (Reilly et al., 2015). The sewage sludge used to inoculate dark fermentation and anaerobic digestion was collected from a local sewage treatment works (Cog Moors, UK). The Cog Moors anaerobic digester was fed sewage sludge and was operated at $35^{\circ} \mathrm{C}$ with a hydraulic retention time of 16 days. Before use the sewage sludge was put through a $500 \mu \mathrm{m}$ sieve to ensure homogeneity.

During Experiment A, fresh inoculum was collected on 12 separate occasions from March 2013 to October 2014. Two further collections of inoculum (B1 \& B2) were used for Experiment B. Inoculums B1 and B2 were used when the initial $\mathrm{pH}$ of the dark fermentation stage was adjusted to $\mathrm{pH} 6.25$ and 7. A summary of the characteristics of the sewage sludge inoculum after sieving is presented in Table 1.

\subsection{Biomethane potential (BMP) tests}

BMP tests were completed according to the method of Reilly et al., (2015). Each bioreactor consisted of an airtight $600 \mathrm{~mL}$ glass duran bottle, which was continuously stirred by an over-head motor (connected to a sealed impeller). The bottles were purged with $300 \mathrm{~mL}$ of $\mathrm{N}_{2}$ before being placed in a $35^{\circ} \mathrm{C}$ water bath for a period of 30 days. During Experiment A the amounts sieved inoculum and cellulose were kept at a VS 
ratio of 1.5:1 unless otherwise stated. Deionised water $\left(\mathrm{diH}_{2} \mathrm{O}\right)$ was used when required to top up the working volume in the BMP bioreactors to $500 \mathrm{~mL}$. Experiment $\mathrm{B}$ tested the influence of sewage sludge inoculum, which is carried over from dark fermentation stage, on single-stage BMP from cellulose. Table 2 presents the contents of bioreactor used for BMP tests in Experiment B.

All sets of conditions for BMP tests were set-up in triplicate, with the exception of two cellulose controls used for Experiment A, which were taken from Reilly et al., (2015) when duplicate controls had been completed in some cases. In both of Experiments A and B blank bioreactors were setup, which contained the same volume of methanogenic inoculum, but without the addition of either cellulose or dark fermentation effluent. These methanogenic inoculum-only blanks were also topped up to $500 \mathrm{~mL}$ with $\mathrm{diH}_{2} \mathrm{O}$.

\subsection{Generation of dark fermentation effluent}

Dark fermentation was carried out using a method adapted from Reilly et al., (2014). In brief, the sewage sludge was heated in a 15 psi pressure cooker for 60 minutes. Heattreatment was applied to suppress methanogenesis and select for spore-forming clostridia which produce biohydrogen. $2 \mathrm{~g}$-VS of the heat-treated inoculum was added to each bottle and topped up to $500 \mathrm{~mL}$ with $\mathrm{diH}_{2} \mathrm{O} . \mathrm{CO}_{2}$ gas was bubbled through the bioreactor to adjust the $\mathrm{pH}$ of the working volume to either 6.25 or $7 . \mathrm{CO}_{2}$ was also used to create anaerobic conditions in the headspace as per Reilly et al., (2014). The dark fermentation experiments were operated at $35^{\circ} \mathrm{C}$ for 44 hours in the same bioreactor equipment which was used in the current study for the BMP testing i.e. continuously stirred and air-tight $600 \mathrm{~mL}$ glass bottles. Dark fermentation bioreactors which contained $2.5 \mathrm{~g}$-VS of sucrose were setup as triplicate positive controls. 
All sets of conditions used for inoculum-only dark fermentation blank experiments were completed in quadruplicate to provide the amount of sample required for addition to cellulose BMP tests and non-cellulose blanks in Experiment B (Table 2). The quadruplicate of inoculum-only blank dark fermentation bioreactors were pooled. This was performed to minimise any uncontrolled experimental error, when assessing the effects of adding effluent from dark fermentation inoculum to BMP tests.

\subsection{Analytical methods}

Biohydrogen and biomethane production were continuously monitored using wet-tip flow meters and $\mathrm{NaOH} \mathrm{CO}$-scrubbing as per Reilly et al., (2014) and Reilly et al., (2015), respectively. Gas composition in the bioreactor headspace was analysed by gas chromatography, using the same methodology as Devlin et al., (2011). Specific gas production was attributed to cellulose and sucrose by subtracting the gas produced from the sewage sludge inoculum blanks. All values for gas yields were normalised to $20^{\circ} \mathrm{C}$ and $1 \mathrm{~atm}$. Gas yields are presented in terms of per gram of VS.

The $\mathrm{pH}$ of the inoculums and bioreactor contents were determined using a MettlerToledo $^{\mathrm{TM}}$ FG2 FiveGo $\mathrm{pH}$ probe (Mettler-Toledo Ltd., UK). A 2-point calibration was carried out prior to each use of the $\mathrm{pH}$ probe using standards of 4.01 (51302069, Mettler-Toledo Ltd., UK) and 7 (51302047, Mettler-Toledo Ltd., UK). Total solids and VS were calculated according to the standard method procedure (APHA, 1989). VFA concentrations of acetic, propionic, $i$-butyric, $n$-butyric, $i$-valerate and $n$-valerate were measured using the method outlined by Cruwys, et al., (2002). All measurements of chemical composition were carried out in duplicate and the mean average taken for each parameter. 


\section{Results and Discussion}

\subsection{The influence of the volume of anaerobic digester inoculum on BMP yields from cellulose (Experiment A).}

Fig. 1 shows the BMP yields from anaerobic digestion of cellulose and the residual biomethane production from each sewage sludge inoculum blank. The volume of inoculum used was determined by the VS concentration in the feedstock being trialled at the time, alongside each cellulose control. It is important to note that there is no relationship between the volume of sewage sludge used for the BMP test and the order of data collection.

The data presented in Fig. 1 suggests that an upward trend exists between the BMP yield from the cellulose and the volume of methanogenic sewage sludge inoculum, which is initially incorporated into the digester total working volume. Alternatively the dilution of the process with $\mathrm{H}_{2} \mathrm{O}$ may cause the final BMP yield from cellulose to decrease, this will be discussed later.

Step-wise increments in average biomethane yield from cellulose were observed when the volume of sludge inoculum was increased between $63 \mathrm{~mL}$ and $400 \mathrm{~mL}$. Across the entire range of inoculum volumes used for the BMP tests, the biomethane yields from cellulose varied between $260 \pm 8 \mathrm{NmL}^{-\mathrm{CH}_{4}}{\mathrm{~g}-\mathrm{VS}^{-1}}$ and $392 \pm 18 \mathrm{NmL}^{-\mathrm{CH}_{4}} \mathrm{~g}-\mathrm{VS}^{-1}$. These lowest and highest yields from cellulose were obtained when $63 \mathrm{~mL}$ and $400 \mathrm{~mL}$ of sludge inoculum were used, respectively. Even though the average biomethane yield from cellulose was reduced by as much as $132 \pm 26 \mathrm{NmL}_{-} \mathrm{CH}_{4} \mathrm{~g}-\mathrm{VS}^{-1}$ when the volume of inoculum was lowest, no accumulation of VFAs resulted throughout data collection for Fig. 1. This absence of VFA accumulation indicates that digester overloading was 
not responsible for the observed reduction in biomethane yields. The maximum range between the average residual biomethane yields from the blank controls throughout

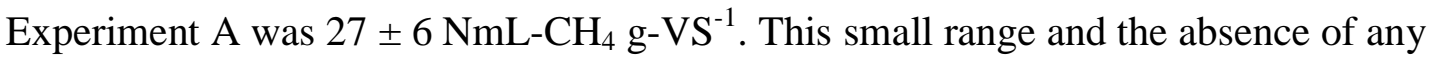
obvious trends in residual biogas yields show that the source of inoculum remained sufficiently consistent (Fig. 1).

The Experiment A data set includes the use of $200 \mathrm{~mL}$ volumes of sewage sludge inoculum when applying inoculum:substrate VS loading ratios of 1.5 and 3.5. It can be seen in Fig. 1 that when the VS loading ratio was changed, whilst keeping the volume of inoculum constant, the average biomethane yields from the cellulose control substrate remained similar (with an average difference of $20 \pm 9 \mathrm{NmL}_{-} \mathrm{CH}_{4} \mathrm{~g}-\mathrm{VS}^{-1}$ ). This similarity supports a hypothesis that the apparent variations in cellulose yields in Fig. 1 were directly related to the volume of sludge inoculum rather than inoculum:substrate VS loading ratio. It is also worth noting that at the higher inoculum VS loading ratio of 3.5:1 more nutrients would have been available per $\mathrm{g}$ of cellulose added, than when using a ratio of 1.5:1 (Wan et al., 2011). This provides evidence that total nutrient availability was not responsible for limiting biomethane yields. One possible hypothesis is that when the inoculum is diluted, a greater amount of the carbon substrate is fixed into microbial biomass. The dilution could provide an unoccupied niche which triggers a greater ratio of cells to fix the substrate carbon into new growth of biomass.

The influence of initial inoculum volume could be contributing to some of the variations in BMP yields which have been previously reported from similar feedstocks (De la Rubia, et al.,2011). The results presented here suggest that in order to achieve maximum 
yields from single-stage BMP tests, extensive dilution of sewage sludge digester inoculum should be avoided. Although the current study shows that biomethane yields can be influenced by the volumetric ratio of inoculum to working volume, from the results there is no evidence to suggest that a relative comparison between single-stage BMP from substrates can't be made fairly. However based on the current study it can be recommend that the volume of inoculum used should remain consistent when making such comparisons. The results of Experiment A raise the following question. How does the inevitable carryover of inoculum from dark fermentation in a two-stage batch study influence the biomethane production stage?

\subsection{The influence of dark fermentation inoculum-only blank effluent on single- stage BMP yields from cellulose (Experiment B)}

The results from Experiment A showed that the volume of anaerobic digestion sewage sludge, used to inoculate single-stage BMP tests can influence the biomethane yields when using cellulose as a substrate. Further experiments were subsequently designed to investigate if the selection of a biohydrogen producing microbial consortium (by heattreatment) and dark fermentation changes the effect of the sewage sludge inoculum on methanogenic yields. Additionally, the influence of varying the volume of methanogenic sewage sludge, on the biomethane yields from cellulose, was reexamined simultaneously while using the same sample of inoculum.

\subsubsection{Dark fermentation of sucrose and inoculum-only blank}

Any biohydrogen production from the inoculum-only blank dark fermentation reactors was below the wet-tip flow meters detectable limits (less than $12 \mathrm{~mL}$ ). This was not unexpected as the absence of gas flow from the inoculum-only blanks was reported 
previously by Reilly et al., (2014). Observations by Reilly et al., (2014) led to the premise of incorporating the sucrose-fed controls in to the current study for confirmation that heat pre-treatment and dark fermentation of the inoculum were reliable. The level of biohydrogen production from the sucrose-fed dark fermentation reactors is illustrated in Fig. 2. At the end of the batch biohydrogen fermentation, analysis of the final bioreactor headspace gas composition detected no presence of methane. This absence of methane confirmed that methanogenesis was inhibited by the heat pre-treatment of the inoculum. The average biohydrogen yields from sucrose were

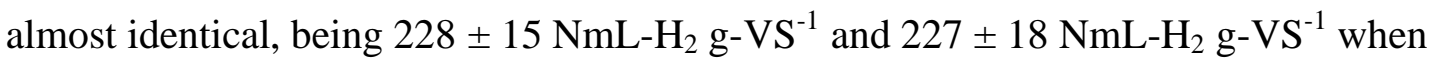
the initial fermentation $\mathrm{pH}$ had been adjusted to 6.25 and 7 , respectively. A close similarity of the sucrose yields with those reported by other investigators (generally between $185 \mathrm{~mL}-\mathrm{H}_{2} \mathrm{~g}-\mathrm{VS}^{-1}$ and $262 \mathrm{~mL}-\mathrm{H}_{2} \mathrm{~g}-\mathrm{VS}^{-1}$ ) illustrates that the preparation of inoculum and dark fermentation methodology used here, are not untypical of those applied by the wider research community (Chen et al., 2006; Mu et al., 2006; Zhang et al., 2005).

Table 3 summarises the chemical characteristics of the effluents from dark fermentation. In all cases the average $\mathrm{pH}$ dropped during the 44 hour dark fermentation period. The results show that the decline in $\mathrm{pH}$ was greater in the sucrose fed bioreactors than in the inoculum-only blank reactors. In the sucrose reactors the $\mathrm{pH}$ declined to 4.39 and 4.47 , while the $\mathrm{pH}$ in the inoculum-only blank reactors declined to 6.12 and 6.72 , after starting the dark fermentation process at 6.25 and 7 , respectively. This decline in $\mathrm{pH}$ has been well documented and can be explained by the large enhancement in the concentrations of acetic and butyric acids which result from the conversion of the sugar to VFA during dark fermentation (Chen et al., 2006; Liu et al., 2006; Mu et al., 2006; 
Zhang et al., 2005). Total VFA concentration after dark fermentation was 4.65 times higher on average when sucrose was fed to the inoculum (Table 3). VS contents in the bioreactors decreased during dark fermentation. The content of the sucrose fed bioreactors the overall concentration of VS declined from $9 \mathrm{~g}-\mathrm{VS} \mathrm{L}^{-1}$ to $6.64 \pm 0.90$ and $6.76 \pm 0.13 \mathrm{~g}-\mathrm{VS} \mathrm{L}{ }^{-1}$, during dark fermentation started at $\mathrm{pH} 6.25$ and 7, respectively. The final VS concentrations in the blank reactors containing inoculum-only decreased from $4 \mathrm{~g}$-VS L $\mathrm{L}^{-1}$ to $3.79 \pm 0.07$ and $3.72 \pm 0.14 \mathrm{~g}$-VS L ${ }^{-1}$ after beginning the dark fermentation at $\mathrm{pH} 6.25$ and 7 , respectively.

\subsubsection{Biomethane production from cellulose}

The data displayed in Fig. 3 confirms that increasing the volume of methanogenic inoculum raises the average biomethane yield from the single-stage anaerobic digestion fed on cellulose. When $200 \mathrm{~mL}$ of sewage sludge methanogenic inoculum was diluted and used in the $500 \mathrm{~mL}$ total working volume, the yield from cellulose was $342 \pm 12$ $\mathrm{NmL}-\mathrm{CH}_{4} \mathrm{~g}-\mathrm{VS}^{-1}$. In comparison, the bioreactors, which contained $500 \mathrm{~mL}$ of undiluted sewage sludge methanogenic inoculum, achieved an 11.4\% higher average yield of 381 $\pm 22 \mathrm{NmL}_{-} \mathrm{CH}_{4} \mathrm{~g}-\mathrm{VS}^{-1}$.

Two batches of fresh sewage sludge inoculum (B1 \& B2) were used in Experiment B, one for each initial $\mathrm{pH}$ that was applied during the generation of dark fermentation effluent. Therefore the biomethane production from cellulose, with $200 \mathrm{~mL}$ of methanogenic inoculum added, was used as methanogenesis controls. In Fig. 4 it can be seen that the average specific biomethane production $\left(342 \pm 12 \mathrm{NmL}_{-} \mathrm{CH}_{4} \mathrm{~g}_{-} \mathrm{VS}^{-1}\right.$ and

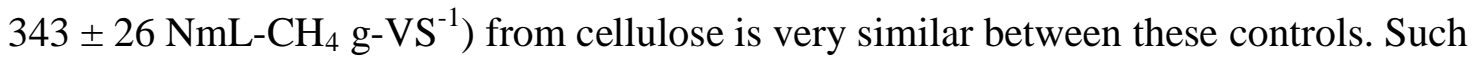


a close similarity infers that the comparisons made between changing the $\mathrm{pH}$ at the beginning of the dark fermentation process are reliable.

The addition of effluent from the inoculum-only blank dark fermentation process increased the specific biomethane yield during the single-stage digestion of cellulose (Fig. 4). Due to the introduction of inoculum, which had been conditioned for biohydrogen production, the gas flow was regularly tested for $\mathrm{H}_{2}$ in the initial stages of the BMP tests. Periodic testing of the gas composition in the bioreactor headspace confirmed the occurrence of methanogenesis from the start of the BMP test. By adding $300 \mathrm{~mL}$ of dark fermentation effluent (instead of $\mathrm{diH}_{2} \mathrm{O}$ ) to the single-stage anaerobic digestion, the specific biomethane yield attributed to cellulose was enhanced by up to $18.8 \%$. Although the highest increase in specific biomethane yields were observed when the production of dark fermentation effluent had been initiated at $\mathrm{pH} 6.25$, a 7\% increase in the biomethane yield from cellulose was also recorded when the starting $\mathrm{pH}$ of the dark fermentation was 7.

Final $\mathrm{pH}$ values for the digestates at the end of all BMP tests were between 6.94 and 7.39 throughout Experiment B, within the range that methanogenesis proceeds uninhibited (Lay et al., 1997). Furthermore, no accumulation of VFA was found in the BMP bottles and therefore digester overloading did not occur (Massanet-Nicolau et al., 2013). Hence, the precise reason for why specific biomethane yields were found to be greater after increasing the volume of sewage sludge inoculum either directly or via dark fermentation, remains unexplained. Nevertheless, the results collected in the current study suggest that the typical batch methodologies which have been previously used to compare energy yields between single-stage and two-stage anaerobic digestion 
may favour two-stage processes. This is because the single-stage has often been diluted with $\mathrm{H}_{2} \mathrm{O}$ to standardise the working volumes between methanogenesis of dark fermentation effluent or anaerobic digestion of the initial feed substrate (Kim et al., 2013; Pakarinen et al., 2011, 2009; Yang et al., 2011). While it has been shown here that diluting the concentration of digester inoculum can decrease the biomethane yield from feed substrates in a single-stage BMP test, the results also demonstrate that the carryover of inoculum from dark fermentation can be beneficial for the methanogenesis process. Therefore it important for the research community to reconsider how gas yields are specifically attributed to feed substrates in two-stage batch studies.

The findings reported here suggest that in batch studies where the two-stage specific yields have been reported to be higher than those from single-stage are a systematic over-estimation. The two-stage improvement in yields in these cases may have been significantly reduced or even non-existent, had an additional amount of the source of inoculum been added to the single-stage comparison. Further work is required to further test this hypothesis and more research is needed to fully describe the mechanisms behind the effect of sewage sludge concentration on the specific BMP yields. However, the influence of sewage sludge concentration should be considered when making design decisions based only on batch study data and suggests if possible all design or economic decisions should be based on continuously operated reactors in either continuously fed or fed batch mode.

When conducting batch studies, it is recommend that investigators should include controls such as those in this study, which account for influences of the carryover of inoculum from the dark fermentation stage into the methanogenesis stage. In addition 
both single-stage and two-stage batch tests should be optimised before being compared, as suggested by Schievano et al., (2014). Furthermore, we advise that BMP measurements, without the addition of $\mathrm{H}_{2} \mathrm{O}$ to either the inoculum or feed substrate, should be included when seeking to optimise the single-stage BMP.

\section{Conclusions}

Carryover of sewage sludge inoculum from dark-fermentation increased single-stage biomethane production from cellulose. This is a significant finding, because increasing the concentration of methanogenic sewage-sludge inoculum in methane batch digestion also improved biomethane yields. As far as the authors are aware, this is a phenomena which has not previously been controlled for in any reported single-stage vs. two-stage comparative batch studies to date. Therefore there is the potential for experimental bias in favour of two-stage systems in experiments where $\mathrm{H}_{2} \mathrm{O}$ has been added to standardise the working volume of the single-stage anaerobic digestion comparison. 


\section{References}

1. Alzate, M.E., Muñoz, R., Rogalla, F., Fdz-Polanco, F., Pérez-Elvira, S.I., 2012. Biochemical methane potential of microalgae: Influence of substrate to inoculum ratio, biomass concentration and pretreatment. Bioresour. Technol. 123, 488-494. doi:http://dx.doi.org/10.1016/j.biortech.2012.06.113

2. Angelidaki, I., Alves, M., Bolzonella, D., Borzacconi, L., Campos, J.L., Guwy, A.J., Kalyuzhnyi, S., Jenicek, P., Van Lier, J.B., 2009. Defining the biomethane potential (BMP) of solid organic wastes and energy crops: A proposed protocol for batch assays. Water Sci. Technol. 59, 927-934. doi:10.2166/wst.2009.040

3. APHA Standard Methods for the Examination of Water and Wastewater, 17th ed, 1989. . American Public Health Association, Washington DC.

4. Chen, W.-H., Chen, S.-Y., Khanal, S.K., Sung, S., 2006. Kinetic study of biological hydrogen production by anaerobic fermentation. Int. J. Hydrogen Energy 31, 2170-2178. doi:http://dx.doi.org/10.1016/j.ijhydene.2006.02.020

5. Cheng, X.-Y., Liu, C.-Z., 2012. Enhanced coproduction of hydrogen and methane from cornstalks by a three-stage anaerobic fermentation process integrated with alkaline hydrolysis. Bioresour. Technol. 104, 373-379.

doi:http://dx.doi.org/10.1016/j.biortech.2011.10.082

6. Cruwys, J.A., Dinsdale, R.M., Hawkes, F.R., Hawkes, D.L., 2002. Development of a static headspace gas chromatographic procedure for the routine analysis of volatile fatty acids in wastewaters. J. Chromatogr. A 945, 195-209. doi:10.1016/S00219673(01)01514-X

7. De la Rubia, M.A., Fernández-Cegrí, V., Raposo, F., Borja, R., 2011. Influence of particle size and chemical composition on the performance and kinetics of anaerobic digestion process of sunflower oil cake in batch mode. Biochem. Eng. J. 58-59, 162-167. doi:http://dx.doi.org/10.1016/j.bej.2011.09.010

8. Dechrugsa, S., Kantachote, D., Chaiprapat, S., 2013. Effects of inoculum to substrate ratio, substrate mix ratio and inoculum source on batch co-digestion of grass and pig manure. Bioresour. Technol. 146, 101-108. doi:http://dx.doi.org/10.1016/j.biortech.2013.07.051

9. Devlin, D.C., Esteves, S.R.R., Dinsdale, R.M., Guwy, A.J., 2011. The effect of acid pretreatment on the anaerobic digestion and dewatering of waste activated sludge. Bioresour. Technol. 102, 4076-4082.

10. Eskicioglu, C., Ghorbani, M., 2011. Effect of inoculum/substrate ratio on mesophilic anaerobic digestion of bioethanol plant whole stillage in batch mode. Process Biochem. 46, 1682-1687. doi:http://dx.doi.org/10.1016/j.procbio.2011.04.013 
11. Giordano, A., Cantù, C., Spagni, A., 2011. Monitoring the biochemical hydrogen and methane potential of the two-stage dark-fermentative process. Bioresour. Technol. 102, 4474-4479.

12. Giordano, A., Sarli, V., Lavagnolo, M.C., Spagni, A., 2014. Evaluation of aeration pretreatment to prepare an inoculum for the two-stage hydrogen and methane production process. Bioresour. Technol. 166, 211-218. doi:http://dx.doi.org/10.1016/j.biortech.2014.05.019

13. Kaparaju, P., Serrano, M., Thomsen, A.B., Kongjan, P., Angelidaki, I., 2009. Bioethanol, biohydrogen and biogas production from wheat straw in a biorefinery concept. Bioresour. Technol. 100, 2562-2568. doi:http://dx.doi.org/10.1016/j.biortech.2008.11.011

14. Kim, M., Liu, C., Noh, J.-W., Yang, Y., Oh, S., Shimizu, K., Lee, D.-Y., Zhang, Z., 2013. Hydrogen and methane production from untreated rice straw and raw sewage sludge under thermophilic anaerobic conditions. Int. J. Hydrogen Energy 38, 8648-8656. doi:http://dx.doi.org/10.1016/j.ijhydene.2013.04.079

15. Kim, M., Yang, Y., Morikawa-Sakura, M.S., Wang, Q., Lee, M. V, Lee, D.-Y., Feng, C., Zhou, Y., Zhang, Z., 2012. Hydrogen production by anaerobic codigestion of rice straw and sewage sludge. Int. J. Hydrogen Energy 37, 3142-3149. doi:http://dx.doi.org/10.1016/j.ijhydene.2011.10.116

16. Lay, J.-J., Li, Y.-Y., Noike, T., 1997. Influences of $\mathrm{pH}$ and moisture content on the methane production in high-solids sludge digestion. Water Res. 31, 1518-1524. doi:http://dx.doi.org/10.1016/S0043-1354(96)00413-7

17. Liu, Dawei, Liu, Dapeng, Zeng, R.J., Angelidaki, I., 2006. Hydrogen and methane production from household solid waste in the two-stage fermentation process. Water Res. 40, 2230-2236.

18. Liu, G., Zhang, R., El-Mashad, H.M., Dong, R., 2009. Effect of feed to inoculum ratios on biogas yields of food and green wastes. Bioresour. Technol. 100, 51035108. doi:http://dx.doi.org/10.1016/j.biortech.2009.03.081

19. Liu, Z., Li, Q., Zhang, C., Wang, L., Han, B., Li, B., Zhang, Y., Chen, H., Xing, X.H., 2014. Effects of operating parameters on hydrogen production from raw wet steam-exploded cornstalk and two-stage fermentation potential for biohythane production. Biochem. Eng. J. 90, 234-238. doi:http://dx.doi.org/10.1016/j.bej.2014.06.013

20. Mamimin, C., Singkhala, A., Kongjan, P., Suraraksa, B., Prasertsan, P., Imai, T., OThong, S., 2015. Two-stage thermophilic fermentation and mesophilic methanogen process for biohythane production from palm oil mill effluent. Int. J. Hydrogen Energy 40, 6319-6328. doi:http://dx.doi.org/10.1016/j.ijhydene.2015.03.068 
21. Massanet-Nicolau, J., Dinsdale, R., Guwy, A., Shipley, G., 2013. Use of real time gas production data for more accurate comparison of continuous single-stage and two-stage fermentation. Bioresour. Technol. 129, 561-567. doi:http://dx.doi.org/10.1016/j.biortech.2012.11.102

22. Mu, Y., Wang, G., Yu, H.-Q., 2006. Response surface methodological analysis on biohydrogen production by enriched anaerobic cultures. Enzyme Microb. Technol. 38, 905-913. doi:http://dx.doi.org/10.1016/j.enzmictec.2005.08.016

23. Pakarinen, O.M., Kaparaju, P.L.N., Rintala, J.A., 2011. Hydrogen and methane yields of untreated, water-extracted and acid $(\mathrm{HCl})$ treated maize in one- and twostage batch assays. Int. J. Hydrogen Energy 36, 14401-14407. doi:http://dx.doi.org/10.1016/j.ijhydene.2011.08.028

24. Pakarinen, O.M., Tahti, H.P., Rintala, J.A., 2009. One-stage H2 and CH4 and twostage $\mathrm{H} 2+\mathrm{CH} 4$ production from grass silage and from solid and liquid fractions of $\mathrm{NaOH}$ pre-treated grass silage. Biomass Bioenergy 33, 1419-1427.

25. Patterson, T., Esteves, S., Dinsdale, R., Guwy, A., Maddy, J., 2013. Life cycle assessment of biohydrogen and biomethane production and utilisation as a vehicle fuel. Bioresour. Technol. 131, 235-245.

doi:http://dx.doi.org/10.1016/j.biortech.2012.12.109

26. Raposo, F., Borja, R., Martín, M.A., Martín, A., de la Rubia, M.A., Rincón, B., 2009. Influence of inoculum-substrate ratio on the anaerobic digestion of sunflower oil cake in batch mode: Process stability and kinetic evaluation. Chem. Eng. J. 149, 70-77. doi:http://dx.doi.org/10.1016/j.cej.2008.10.001

27. Reilly, M., Dinsdale, R., Guwy, A., 2014. Mesophilic biohydrogen production from calcium hydroxide treated wheat straw. Int. J. Hydrogen Energy 39, 16891 16901. doi:http://dx.doi.org/10.1016/j.ijhydene.2014.08.069

28. Reilly, M., Dinsdale, R., Guwy, A., 2015. Enhanced biomethane potential from wheat straw by low temperature alkaline calcium hydroxide pre-treatment. Bioresour. Technol. 189, 258-265. doi:http://dx.doi.org/10.1016/j.biortech.2015.03.150

29. Schievano, A., Tenca, A., Lonati, S., Manzini, E., Adani, F., 2014. Can two-stage instead of one-stage anaerobic digestion really increase energy recovery from biomass? Appl. Energy 124, 335-342. doi:http://dx.doi.org/10.1016/j.apenergy.2014.03.024

30. Wan, C., Zhou, Q., Fu, G., Li, Y., 2011. Semi-continuous anaerobic co-digestion of thickened waste activated sludge and fat, oil and grease. Waste Manag. 31, 17521758. doi:http://dx.doi.org/10.1016/j.wasman.2011.03.025

31. Wang, Z., Shao, S., Zhang, C., Lu, D., Ma, H., Ren, X., 2015. Pretreatment of vinegar residue and anaerobic sludge for enhanced hydrogen and methane 
production in the two-stage anaerobic system. Int. J. Hydrogen Energy 40, 44944501. doi:http://dx.doi.org/10.1016/j.ijhydene.2015.02.029

32. Xie, B., Cheng, J., Zhou, J., Song, W., Liu, J., Cen, K., 2008. Production of hydrogen and methane from potatoes by two-phase anaerobic fermentation. Bioresour. Technol. 99, 5942-5946.

doi:http://dx.doi.org/10.1016/j.biortech.2007.10.048

33. Yang, Z., Guo, R., Xu, X., Fan, X., Luo, S., 2011. Hydrogen and methane production from lipid-extracted microalgal biomass residues. Int. J. Hydrogen Energy 36, 3465-3470. doi:http://dx.doi.org/10.1016/j.ijhydene.2010.12.018

34. Zhang, Y., Liu, G., Shen, J., 2005. Hydrogen production in batch culture of mixed bacteria with sucrose under different iron concentrations. Int. J. Hydrogen Energy 30, 855-860. doi:http://dx.doi.org/10.1016/j.ijhydene.2004.05.009 
Tables and figure legends

Table 1. The chemical characteristics of freshly collected anaerobic sewage sludge inoculums for experiments A, B1 and B2. Values represent averages of triplicate independent repeats \pm standard deviations.

Table 2. The bioreactor contents for single-stage biomethane potential tests in Experiment B. Each bioreactor was also set-up without the addition of cellulose to provide inoculum-only blank measurements.

Table 3. The characteristics of dark fermentation effluent from sucrose-fed and inoculum-only blank bioreactors initiated a pH 6.25 or 7 .

Fig. 1. Specific biomethane production from single-stage anaerobic digestion of cellulose and the sewage sludge inoculum used for blanks. The ratios indicate volatile solid (VS) addition of inoculum to cellulose. In all cases the total working volume was $500 \mathrm{~mL}$ with error bars represent \pm standard deviation.

Fig. 2. Biohydrogen production from sucrose controls when dark fermentation was initiated a pH 6.25 and 7.

Fig. 3. Average biomethane potential from cellulose in bioreactors containing 200 $\mathrm{mL}$ or $500 \mathrm{~mL}$ of sewage sludge methanogenic inoculum (MI) in a $500 \mathrm{~mL}$ total working volume. Average gas production from MI has been subtracted at corresponding time points.

Fig. 4. Average biomethane potential from cellulose in single-stage bioreactors with and without the addition of dark fermentation effluent (DFE). All bioreactors had a working volume of $500 \mathrm{~mL}$. Dark fermentation of inoculum-only blanks was initiated at pH 6.25 or 7 to produce DFE. Average gas production from methanogenic inoculum (MI) and DFE has been subtracted at corresponding time points. Two collections of sewage sludge inoculum were used (B1 \& B2). 


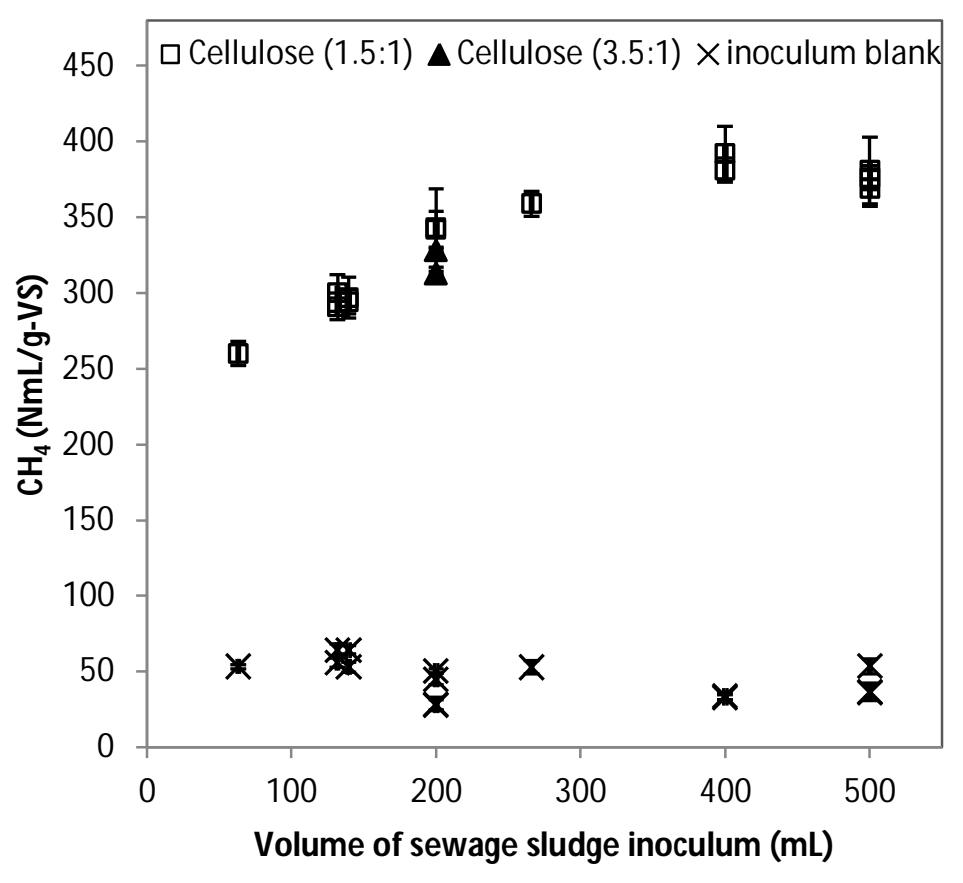


Click here to download Figure: Figure 2.docx

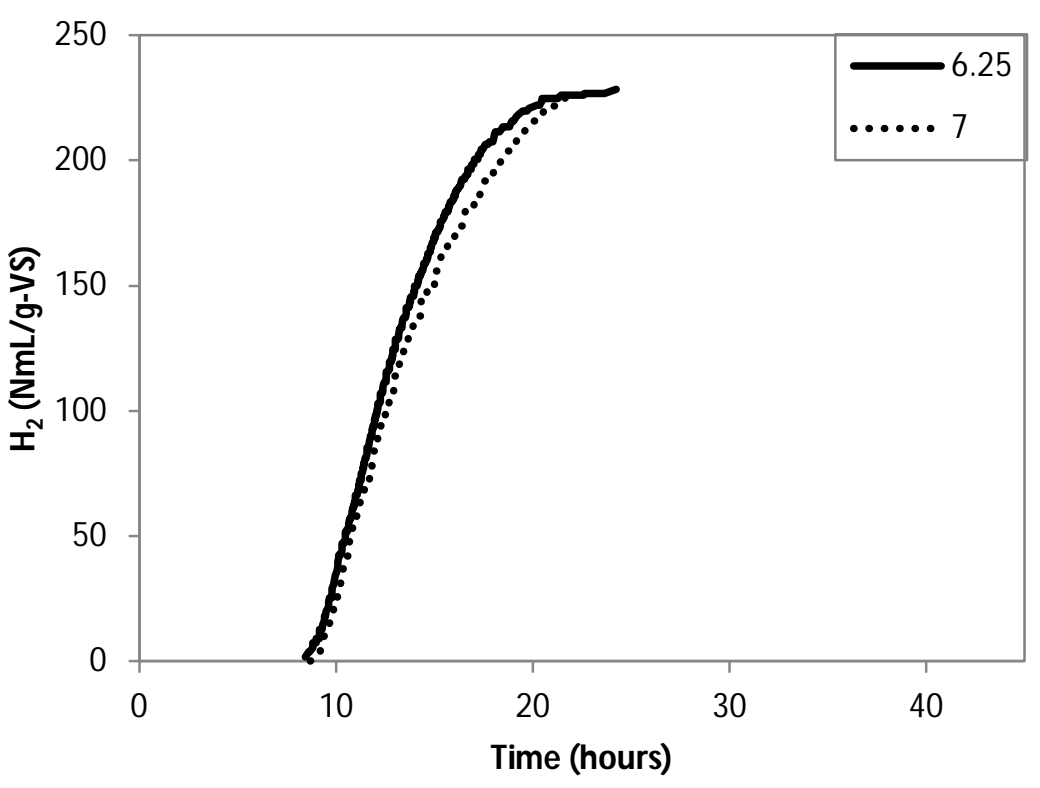


Figure 3

Click here to download Figure: Figure 3.docx

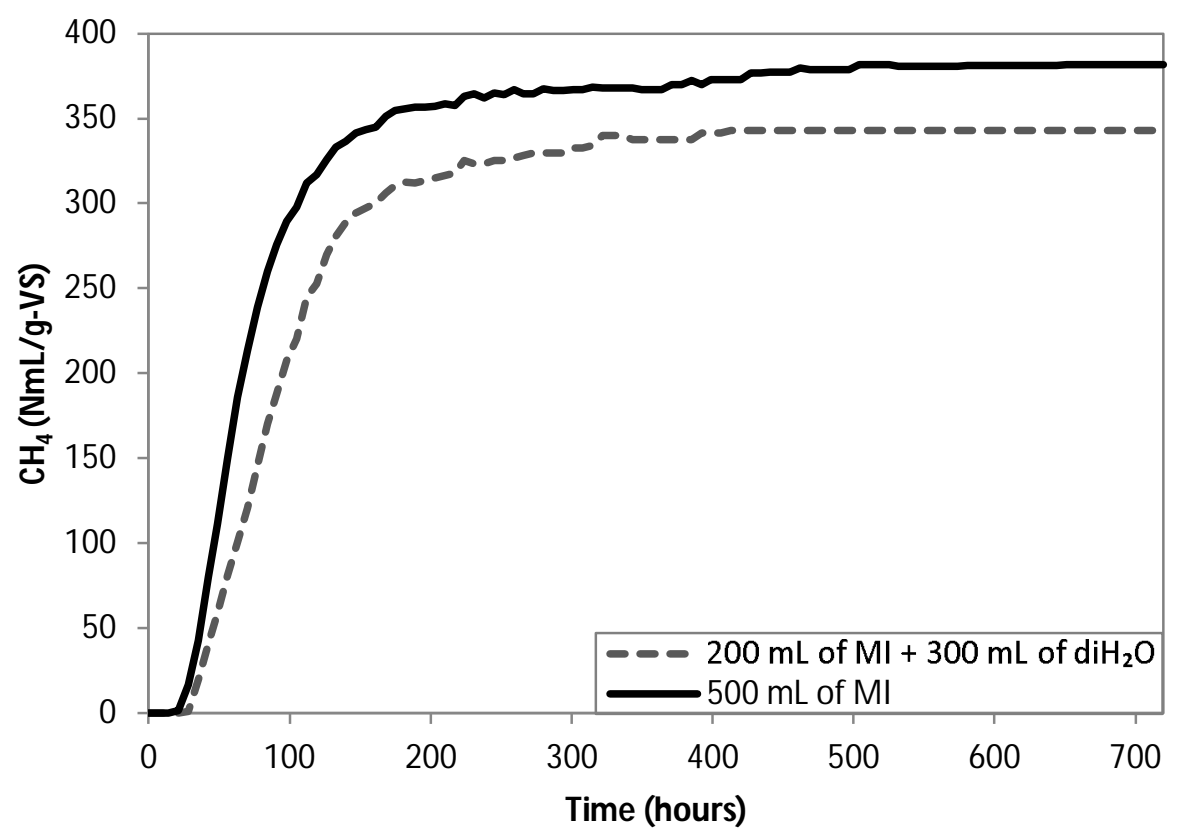


Figure 4

Click here to download Figure: Figure 4.docx

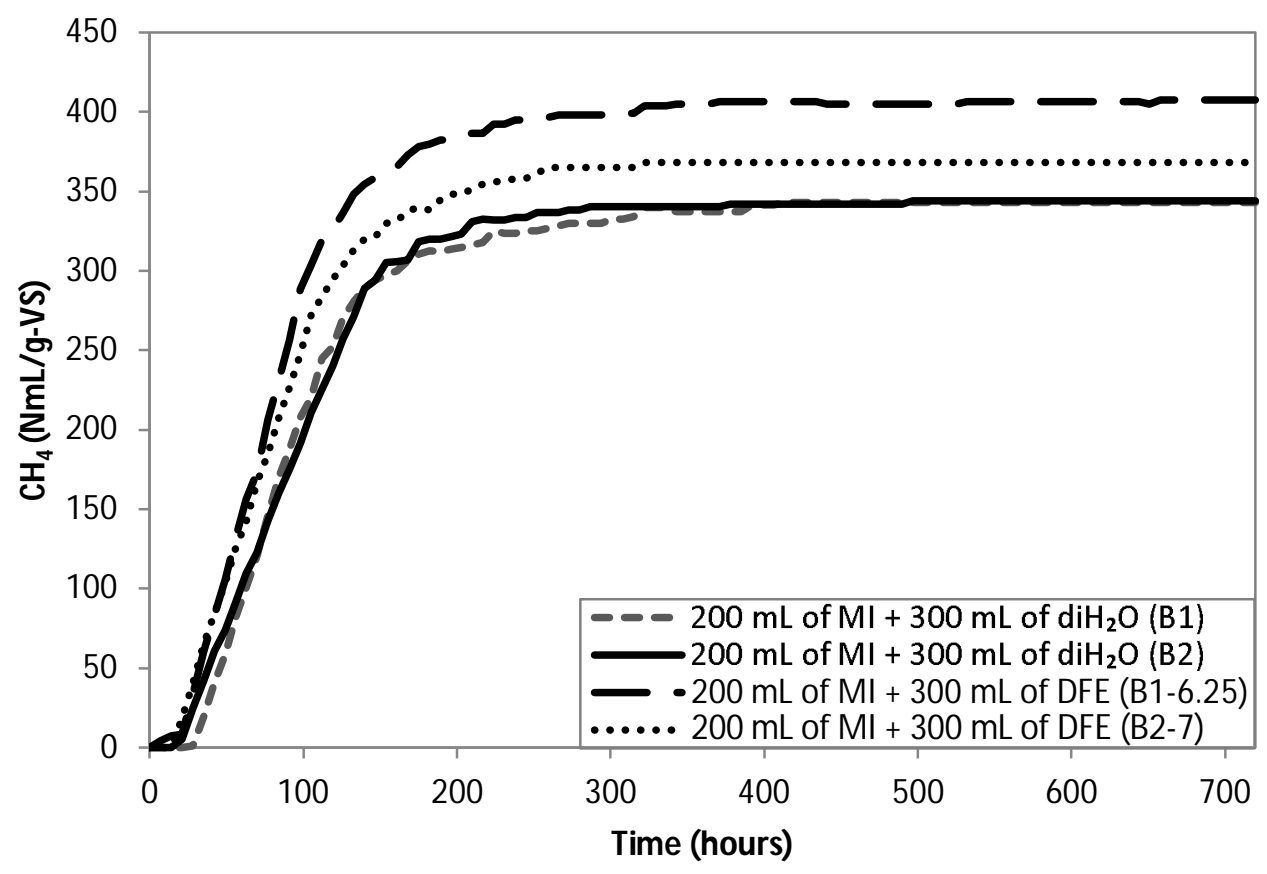




\begin{tabular}{cccc}
\cline { 2 - 4 } & A (12) & B1 (1) & B2 (1) \\
\hline Total Solids (\%) & $3.32 \pm 1.10$ & $3.17 \pm 0.01$ & $3.26 \pm 0.02$ \\
Volatile Solids (\%) & $1.8 \pm 0.50$ & $1.6 \pm 0.03$ & $1.7 \pm 0.02$ \\
pH & $7.33 \pm 0.06$ & $7.32 \pm 0.00$ & $7.33 \pm 0.00$ \\
\hline
\end{tabular}




\begin{tabular}{lllll}
\hline $\begin{array}{l}\text { Sewage sludge } \\
\text { inoculum }\end{array}$ & $\begin{array}{l}\text { Effluent from dark } \\
\text { fermentation of inoculum- } \\
\text { only blank } \\
(\mathbf{m L}-\text { initial pH) }\end{array}$ & $\begin{array}{l}\text { Methanogenic } \\
\text { inoculum }(\mathbf{m L})\end{array}$ & $\begin{array}{l}\mathbf{d i H}_{2} \mathrm{O} \\
(\mathbf{m L})\end{array}$ & $\begin{array}{l}\text { Cellulose } \\
(\mathbf{g}-\mathrm{VS})\end{array}$ \\
\hline B1 & $300-6.25$ & & 0 & \\
B1 & $0--$ & 200 & 0 & 2.22 \\
B1 & $0--$ & 200 & 300 & 2.22 \\
B2 & $300-7$ & 200 & 0 & 2.27 \\
B2 & $0--$ & 200 & 300 & 2.27 \\
\hline
\end{tabular}




\begin{tabular}{lccccc}
\hline \multirow{2}{*}{ Parameter } & \multicolumn{2}{c}{ Sucrose-fed } & & \multicolumn{2}{c}{ Inoculum-only blank } \\
\cline { 2 - 3 } \cline { 6 - 7 } & $\mathbf{6 . 2 5}$ & $\mathbf{7}$ & & $\mathbf{6 . 2 5}$ & $\mathbf{7}$ \\
\hline Final pH & $4.39 \pm 0.02$ & $4.47 \pm 0.03$ & & $6.12 \pm 0.05$ & $6.72 \pm 0.04$ \\
Dry solid (\%) & $0.85 \pm 0.08$ & $0.89 \pm 0.10$ & & $0.59 \pm 0.00$ & $0.58 \pm 0.01$ \\
Volatile solid (\%) & $0.66 \pm 0.09$ & $0.68 \pm 0.13$ & & $0.38 \pm 0.00$ & $0.37 \pm 0.01$ \\
Acetic acid (mg/L) & $593 \pm 59$ & $588 \pm 10$ & & $256 \pm 10$ & $232 \pm 4$ \\
Propionic acid (mg/L) & $27 \pm 5$ & $25 \pm 4$ & & $42 \pm 2$ & $39 \pm 4$ \\
i-Butyric acid (mg/L) & $12 \pm 6$ & $10 \pm 3$ & & $35 \pm 3$ & $32 \pm 5$ \\
n-Butyric acid (mg/L) & $1328 \pm 17$ & $1323 \pm 65$ & & $42 \pm 11$ & $38 \pm 6$ \\
i-Valeric (mg/L) & $16 \pm 7$ & $14 \pm 3$ & & $56 \pm 2$ & $52 \pm 4$ \\
\hline
\end{tabular}

